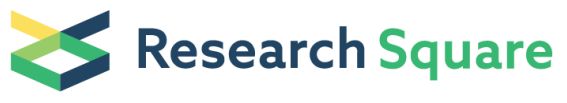 \\ Preprints are preliminary reports that have not undergone peer review. \\ They should not be considered conclusive, used to inform clinical practice, or referenced by the media as validated information.
}

\section{Domestic Violence in Mozambique: From policy to practice}

\author{
Eunice Jethá ( $\sim$ ejetha@yahoo.com.br) \\ Universidade Eduardo Mondlane Faculdade de Medicina \\ Ines Keygnaert \\ International Center for Reproductive Health, Universiteit Gent \\ Emilia Martins \\ Mozambican Institute for Health and Research \\ Mohsin Sidat \\ Universidade Eduardo Mondlane Faculdade de Medicina \\ Kristien Roelens \\ Ghent University, Faculty of Medicine and Health Sciences
}

\section{Research article}

Keywords: Domestic violence, care provision, care providers

Posted Date: January 12th, 2021

DOI: https://doi.org/10.21203/rs.3.rs-26205/v2

License: (c) (i) This work is licensed under a Creative Commons Attribution 4.0 International License. Read Full License 


\section{Abstract}

Background: To reduce the impact of domestic violence (DV), Mozambican governmental and non-governmental entities are making efforts to strengthen the legislative framework and improve the accessibility of care services for survivors of violence. Despite this remarkable commitment, the translation of policies and legislation into actions remains a huge challenge. Therefore, this paper aims to identify gaps in the implementation of existing national policies and laws for DV in the services providing care for survivors of DV.

Methods: This study, using a qualitative approach had two components. The first was content analysis of guidelines and protocols for DV care provision. The second consisted of in-depth interviews with institutional gender focal points. The analysis of the document content was based on a framework developed according to key elements recommended by international agencies (PAHO and UN) for DV policies and strategies design. Data from the in-depth interviews, where analysed in accordance with study objectives.

Results: Eleven (11) guidelines/protocols of care provision and innumerable brochures and pamphlets were identified and analysed. There is a standardised form highlighting the integrated approach incorporating fields for police and the health sector but excludes Civil Society Organisations. However, there is no national DV database specifically for DV. Although the focal points recognised the relevance of the reviewed documents, many identified gaps in implementation. This is related to the weaknesses of the offender's penalisation and to the scarcity of care providers. And, many providers who do exist often lack appropriate training. They also recognised their performance is negatively influenced by socio-cultural factors.

Conclusion: Within services providing care to survivors of DV, a scarcity of guidelines and protocols exist, compromising the quality and standardisation of care. Recognition of the relevance of care guidelines and protocols is a strength, there are challenges that governmental and non-governmental entities must address in order to ensure DV prevention and control strategies have the desired results.

\section{Background}

Domestic violence (DV) is recognised as a complex worldwide problem affecting a large proportion, violating their human rights [1-3]. DV is often defined as an aggression, abuse or threatening behavior between intimate partners or former partners and members of a family occurring in the household [4]. Due to the fact women are often described as survivors, the term DV is often replaced by intimate partner violence, violence against women, spousal or ex spousal violence, family violence and wife assault or abuse. Men are identified as the most frequent perpetrators, although women can also perpetrate violence against men with similar characteristics in terms of severity, consequences, and background causes [5-8]. DV is an important public health issue which in most cases, compromises the women's physical, mental and reproductive health [9-11].

Worldwide, one in three women has physically or has been abused sexually by her intimate partner or family members at some point of her lifetime. According to a World Health Organisation (WHO) multi-country study, the prevalence of women survivors of physical or sexual abuse from their intimate partner was between $15 \%$ ( Japan) and $71 \%$ ( Ethiopia) $[12,13]$

Similarly, compared to the rest of the world, Sub-Saharan African women are more affected by DV than men. The two most common forms of violence against women being intimate partner violence and coercive sex, which are attributed to poverty, as well as to contextual and cultural factors $[14,15]$.

Mozambique is not an exception, according to the Demographic Health Survey (DHS) of 2011, one-third of women (33\%) have been victims of physical violence since the age of 15, at some point in their lives.. Most recently, Malaria, HIV/AIDS, and Immunisation Indicator Survey in Mozambique (IMASIDA) found approximately $24 \%$ of the women interviewed over the age of 15 admitted to being victims of physical (18\%), emotional (15\%) or sexual violence (3\%), at some point of their lives. Although less frequent, approximately $13 \%$ of men reported having been survivors of DV, with the intimate partner as perpetrator $[15,16]$.

Therefore, in Mozambique, the rise of awareness of DV has led the government to place this phenomenon as a priority on its agenda. This has been done, in an attempt to reducing cases of DV and to improve the quality of survivors' lives. To respond to the magnitude of this problem, governmental and non-governmental entities are making efforts to strengthen legislative framework and improve the accessibility of care services for survivors of violence. As a result of this effort, Mozambique has a wide range of legislative measures, produced and approved by the Mozambican government[1].

Apart from this political commitment, identification of the key role institutions for DV-related issues - the Ministry of Gender Child and Social Action, Ministry of the Home affairs, Ministry of Health and Justice as well as the establishment of a network between governmental and/or nongovernmental organisations were the other fundamental aspects taken into account in the design of the Mozambican legal structure for DV prevention, and importantly, control of its implementation $[18,19]$. 
Despite these remarkable efforts, cases of violence are still underreported and neglected [15, 20, 21]. One factor that could be behind this phenomenon, is the recognition of DV as a private matter, with only $10 \%$ of all cases of violence being reported to the police. Most often, survivors appeal to the informal system (community leaders, extended family) to solve the problem [22, 23]. The lack of information on the availability of services and poor quality of services partially explain low reporting and also minimal care-seeking behaviour of DV survivors or their relatives $[12,24,25]$.

Furthermore, policy and legislation translation into actions through development of guidelines or service delivery protocols as well as implementers or care providers, commitment remains an enormous challenge [26].

Therefore, this paper aims to identify gaps in the implementation of existing national policies and laws for DV, developed at the central level. This includes the Ministries of Health, Home affairs, Gender, Children and Social Action, and Civil Society Organisations. Also included are the services providing care for survivors of DV. More specifically, at care provision sites, we first verified the existence of guidelines and protocols on care for DV survivors. Secondly, we analysed the extent to which guidelines and protocols reflected recommendations established in law, policies and strategic plans. Thirdly, we assessed gender institutional focal points' awareness of national policies, laws and strategic plans on DV. Finally, we describe the gender institutional focal points' perception of primary gaps in the implementation of policies, laws and strategic plans regarding DV.

Footnote:

[1] Mozambican Laws and Policies

Laws: Constitution of the Republic (1990); Criminal Code (2014); Family Law (2004); Law on Domestic Violence against Women (2009); Legislation on the Promotion of Protection of the Child's Rights (2009). Policies: Gender Policy and Strategy for its Implementation (2006).

Action/ Strategic plans: Government Five-Year Plan (2015); National Plan of Action for the Prevention and Combat of Violence against Women ( 2007); Health Ministry Strategic Plan (2014); Police of the Republic of Mozambique Strategic Plan (2012); Strategic Plan for Institutional Development of the Ministry of Home Affairs (2014) Program of care for women and children - department of family and children victims of violence (2008); Intersectoral Mechanism of Integrated Attendance of Women Victim of Violence (2012); National Action Plan for the Advancement of Women 2010-2014 (2010); National Strategy for Basic Social Security (2016).

\section{Methods}

\section{Study Sites}

This study was conducted in Maputo City, the capital of Mozambique, located in the Southern part of the country. Our study also took place in Quelimane city, the capital of Zambézia province, located in the centre of Mozambique. According to the last DHS, in Zambézia, 30\% of women were survivors of DV, and 70\% of them revealed they have never asked for help, nor ever told anyone about the episode of violence. In Maputo City where supposedly all care services are based and where probably of access to information is higher, the prevalence of DV was $38 \%$ [16].

The study included institutions, purposely identified due to their responsibility in addressing DV-related issues. Therefore, in the Maputo City Ministry of Gender Child and Social Action, Ministry of Health, Ministry of Home Affairs as well as other governmental institutions at the central level were included. Whereas in Quelimane City, the Provincial Directorate of Gender, Social Action of Zambézia; and the Provincial Directorate of Health of Zambézia[2] were selected [27].

In addition to these institutions at central level of the Mozambican government. other relevant institutions on care provision were visited (see figure 1): Health units of primary, secondary and tertiary level, police stations, departments of attendance of family and children victims of violence, and Civil Society Organisations(CSOs). CSOs are responsible for community-based activities and for social support for DV survivors (the link between community and other care services, such as advocacy, provision of shelter for DV survivors) and collaborate with institutions part of the multisectoral mechanism on survivor's care provision [18, 22, 28]. For this study we will consider CSOs as a non-governmental and non-profit entities that do not represent the governmental entities. CSOs includes formal and informal organisations that act within one thematic area (DV-related issues) or in multiple areas (HIV/AIDS, child marriage, among others) of interest or concern of the society.[29].

\section{Study Procedures}

This study used a qualitative approach for the analysis of the documents and to conduct in-depth interviews with institutional gender focal points. Gender focal points are professionals who should have experience in dealing with DV-related issues, pointed to ensure an integrated 
approach, through the implementation of programs and guidelines in the management of DV cases. The study was conducted between March and June 2017.

To conduct this study the following steps shown in the figure below (figure 02).

Document analysis was based on verifying if the guidelines or protocols reflected the recommendations drawn in the national policies, legislation and strategic action regarding institutional plans.

To facilitate analysis guidelines and protocols, the contents of components recommended by the Pan-American Health Organisation (PAHO) and the United Nations (UN) relating to the design of policies and strategies for DV management were used. These components included document title (naming title), the inclusion of the DV definition, the main strategies especially the integrated approach and the beneficiaries of these documents $[30,31]$.

In addition to the document analysis and in-depth interviews were conducted as shown in figure 3 . An interview guide was developed by the principal investigator and reviewed by the other investigators considering the study objectives. It was tested with professionals providing care to the victims of sexual violence at the Central Hospital in Maputo ( 2 forensic doctors, 1 gynaecologist and 1 paediatric surgeon). After piloting, the guide went through and result in minor revisions of the guide and adopted for the study . To facilitate collecting information, interviews were recorded, taking into account aspects related to confidentiality and anonymity.

All guidelines and protocols of attendance for the care of DV survivors, referred by gender focal points at the governmental central level (Figure 3) were included in the analyses. At the level of care services for DV survivors, all existing guidelines and protocols (physical copies) to provide care to survivors of DV were analysed.

All documents not cited by the focal points or were not designed specifically to provide care to DV survivors, were excluded. At the care services, we also excluded all documents that although referred by gender focal points, were not physically available at these locations.

\section{Selection of the sample}

Document analysis - Data were collected at specific institutions randomly selected using $50 \%$ of all existing care services, based on a sampling program that generates randomness,[32] (See figure 1). A total of thirty-eight (38) care services for survivors of DV were included in the study. Of these, eighteen (18) belong to the Ministry of Health, nine (9) to the Ministry of home affairs, and eleven (11) are CSOs. Specifically, selected institutions included: three (3) general hospitals, two (2) health centres, two (2) integrated service centres, seven (7) police help centres, two (2) Department of attendance for family and children victims of violence and eleven (11) CSOs.

Qualitative interviews - To substantiate results obtained in the document analysis the gender focal points of each institution under study were purposively identified by the responsibility of the institution and then they were invited to participate in the study. Focal points specifically included were police officers, health care professionals and social assistants, who were informed about the study aims by the investigator and field assistant.

All focal points identified had shown their interest in participating in the study, and an appointment was scheduled according to their availability, for interview and verification of guidelines and protocols for care provided to DV survivors.

Interviews were conducted by one trained assistant, and by the principal investigator, in Portuguese, the official language of Mozambique. This language was also spoken by all care providers.

\section{Data analysis}

After identifying the documents, they were entered into an excel sheet, and the word count was considered in this analysis. To standardise this process specific groups were created taking into account each element of the framework mentioned above. Thus, for the naming style, documents such as "Violence Against women", "Violence", "Gender equality", "Family" and "Domestic Violence" were considered for analysis. Beneficiaries considered were: "women", "child", "family" and "population in general". Although women, including young girls and children also part of the family, were approached in separate groups given their specificities regarding DV. Given the relevance of the integrated approach to combating and preventing DV, it has been treated separately. Prevention, Assistance, DV notification, Advocacy, Capacity Building, Monitoring \& Evaluation, Protection and Offender Criminalization were analysed as other strategies.

The various forms of DV, more specifically physical, psychological, sexual and economic violence were taken into consideration. Moreover, "human rights" was also included since DV is defined as a violation of women's human rights. The catch-all category of "other", consists of further forms of DV, such as female genital mutilation, incest, premature marriages[3], trafficking women and moral violence. After this process of

Page $4 / 16$ 
systematising all analysed documents, it was verified as to what extent its content is aligned with national laws, policies and strategic plans dealing with DV.

After conducting in-depth interviews, a deductive content analysis considering study objectives and previous knowledge were performed. This transpired in several steps to obtain critical themes emerging from the data[33]. Firstly, the entire texts, resulting from the transcription of the recorded interviews, were coded to identify the transcripts and guarantee the confidentiality of the participants. Secondly, transcriptions were read thoroughly by one of the authors (EJ) to achieve a sense of the whole and to preliminary generate an initial list of broad thematic codes. The next step was the revisions of the transcripts and discussions by the research team to ensure the information was as refined as possible. Lastly, the transcripts were exported to NVivo version 12 (QSR International Pty Ltd., Doncaster, Australia) and carefully examined contextually using previously published literature on DV. With this process additional codes were added to the coding structure as they emerged, according to figure 4.

Footnotes:

[2] Ministry of Gender Child and Social Action - Responsible for the multisectoral national coordination of all gender-related activities, ensuring the provision of support services for victims of violence and monitoring \& evaluation of the Multisectoral Mechanism for Integrated Care for Women Victims of Violence; Ministry of Health - Responsible for ensuring the access to health care for victims of violence; Ministry of Home Affairs - Responsible for assistance and protection to victims of violence and also for participating in the process of aggressor criminalization; Provincial Directorate of Gender, Social Action of Zambézia - Subordinated to the Ministry of Gender, Child and Social Action, which coordinates the activities ministry related at the provincial level; Provincial Directorate of Health of Zambézia- Subordinated to the Ministry of Health which coordinates health related activities at the provincial level.

[3] Defined by the new law for prevention and combat premature unions, as union between people in whom at least one is a child (under the age of 18), formed with the immediate or future purpose of starting a family[71]

\section{Results}

This section detailed results of the document analysis and in-depth interviews. Acconding to the study objectives, in the document analysis, we will report on the type of document analysed and its alignment with national policies. Comprehensive interviews describe the relevance, gaps and constraints of protocols and guidelines under study. These are taken from the point of view of gender focal points and care provision guideline tools.

\section{Document Analysis}

This study includes approximately 11 guidelines/protocols and many brochures as well as pamphlets, (see Box 1). These documents were designed at the central governmental level to be implemented at the care services level.

However, as we went down to the level of care services, availability and awareness of the existence of some documents such as guidelines, protocols, brochures and pamphlets decreased profoundly.

\section{Alignment of documents with national policies}

\section{Naming style}

Given the use of different themes in analysed documents, the non-standardisation of titles is noteworthy. In the care services for survivors of violence under the responsibility of the ministries of health and home affairs, the most frequent themes found in the title of the reviewed documents were violence in general, gender-based violence and sexual violence. In relation to the CSOs, titles of pamphlets, brochures and strategic plans contained themes encompassing varied problems - DV, sexual violence, violence against the elderly, and trafficking of children.

Box 1: Guidelines or protocols included are in the document review

\section{Definition of domestic violence}

Although the relevance of including the definition of various forms of violence in guiding documents is to provide care of survivors of violence is recognised. However, the majority of reviewed documents do not have the definition in their content. This definition of numerous forms of violence was only included in some IEC materials disseminated by CSOs. 


\section{Main strategies}

\section{Integrated approach}

Guidelines and protocols verified in the health and home affairs institutions are aimed to provide assistance to DV survivors. The violence case notification form is a standardised tool that integrates multiple DV-related issues. This tool was developed through the engagement of multiple sectors, civil society advocates and survivors of DV. In this form, health providers and police have a specific role to play with the survivor including taking full information, and the procedures completed are specifically focused on care provision. Although CSOs have been working with the communities, identifying many cases of DV, they were not included in the violence case notification form, thus leaving them out of the integrated approach.

In health centres and general hospitals, we did not find guidelines or protocols mentioning integrated care. Those which do exist referred to sexual violence in children and adults, more specifically after exposure to HIV/AIDS and are part of a project funded by a Non-Governmental Organisation, Pathfinder International.

\section{Other strategies}

Regarding DV case notification, although there is a standardised form, health and home affairs institutions have their own case book. Advocacy is the main activity of the CSOs not presented in the reviewed documents from other institutions under study. Although capacity building was a daily activity of the institutions under study, we did not find a document which could certify its implementation. However, the opposite was verified on the CSOs.

The Ministry of health was the only institution to present an instrument for monitoring and evaluation of their DV-related activities. Conversely, the same instrument was not found on the health facilities level.

\section{Beneficiaries}

Almost all documents analysed had the general population as beneficiaries. Only one, on sexual violence, indicated the child as the main beneficiary. Since the majority of the CSOs have their pillar based on the human rights of women and children, some of the pamphlets did address aspects related to these specific groups.

\section{In-depth interviews}

\section{Relevance of guidelines and protocols}

Approximately half of the interviewees emphasised the relevance of the documents under analysis. All were unanimous in stating these were crucial to guiding them through the steps to be taken in the management of DV cases.

"The operational plans assist in the implementation of the actions of all stakeholders ... all sectors of both government and civil society are urged to take action in this area based on these instruments", FP_01_GCSAM.

"We actually have everything, within the health facilities, protocols on what you should do. Protocols, for example, for sexual violence management of cases of, what you should do to a victim", FP_02_HM.

In addition to strengthening the care of survivors of violence, the documents under analysis have been described as crucial in publicising laws and raising awareness about DV-related issues.

". ... we took the law, divided it and made brochures with very simple language. So that even people without legal training can understand and reproduce the law...So, we take the results of that research and we transform it into various formats to reach many different target groups ok,FP_01_CSO.

\section{Guidelines, protocols, gaps and constraints}

Although relevance of documents under review has been recognised by some focal points, most of them have cited gaps in the implementation of these protocols and/or flowcharts.

These gaps vary from those related to the documents themselves. For example, gaps related to policies, content, and more specifically, the inclusion or non-inclusion of a DV definition, beneficiaries and main strategies. Besides this gap, there are other related inconsistencies in the process of implementation. These were also described.

\section{Policy Content}


Although this point has been raised a by few focal points (FP_01_CSO, FP_03_CSO and FP_03_CSO). These focal points recognise the law on DV is not perfect. One glaring constraint is related to the design of policies is the penalisation of perpetrators. According to existing focal points, DV is considered a crime. However, some articles of the criminal code do not refer to the penalisation of the perpetrator.

"For example, in the law of violence you have a situation of an article that refers for example to the penal code for this penal code already reviewed, but nevertheless does not tell you to which article. Refer to the penal code that has several articles. This is a gap....", FP_01_CSO.

Moreover, the penal code is unclear regarding crime concealment, leaving some uncertainties in the penalty for third- and fourth-degree victims' relatives.

"....the crime of concealment is penalised. But this article says the following: ... they don't fit into this category; they can't be penalised for these aspects, family members up to third or fourth degree", FP_03_CSO.

Another constraint is the lack of inclusion of field in the standardised form for the registration of procedures carried out by CSOs in DV case management.

".... Where do we fit in? ...... What support has this victim had? For example, where was she/he referred to, then from here where she/he was referred to... and how it was, what was the outcome of this case", FP_05_CSO.

\section{Policy Implementers}

In addition, gaps related to policy implementation, such as the reduced number of care providers for DV survivors, lack of personnel training of DV, and their attitudes and practices were described by gender focal points. Issues related to the context in which the implementation of the policy is framed, were also raised by the focal points. However, more specifically the socio-cultural environment was examined.

Although little is mentioned, the reduced number of human resources allocated to deal with aspects related to DV was noted.

"Some units already have a psychologist; we still do not have them here. Maybe in this part, cases... we can even refer... in the district direction level, we have a psychologist, so we can be referring there", FP_06_HM.

Another of the mentioned aspects is related to the lack of training. This compromises the performance of care providers in the identification of probable survivors of DV and no less importantly, how to manage DV cases.

"...You look and say you slipped with the basin and got the black eye, right? And a good diagnosis is not made to certify if in fact she/he in fact slipped in the stairs and we end up registering with other diagnosis and not the domestic violence. So, there's a lot of work... a lot of work...", FP_01_CSO.

"...So, if you, a care provider is not properly trained, you will not be able to get the victim to open up to you. You will think that she is there in the health unit because she has another concern while she does not. She needs your support much more" FP_02_HM.

Besides the facts mentioned above, most gender focal points inferred that providers' attitudes and practices can also negatively influence their performance as well as compromise the implementation of policies, laws and strategies to prevent and control DV.

"... The big gap is in the health care provider itself. It's sad to say, but we do not have the habit of reading. We do not read, we have the documents there and we do not read and we keep doing...." FP_02_HM.

“...some magistrates who simply do not want to apply the law of violence, although they are ready, too much work being done we still continue to have this question" FP_01_CSO.

"And if the nurse or the technician does not refer her to the office of attendance, to the office of attendance at the district-level, this case is likely to be lost." FP_01_IM.

\section{Policy Implementation}

During interviews with gender focal points, they cited the influence of socio-cultural factors as a barrier to the implementation of policies, laws and strategies to eradicate DV. In addition to the financial status of the victim, most of the focal points pointed to community attitudes and practices in general and more specifically, of the survivors themselves as potential barriers to achieve the expected results.

"But I realised that for example in the peripheral areas I think that poverty influences a lot. Someone who sees that he his mistreating me but gives me bread. And if I leave here, where will I have bread? Where will I have something to wear and where I will have a place to sleep"FP_01_IM. 
"We know that DV is a public crime and that often people do not take it seriously or in consideration... This is their house's problem. It's their home issues... but the person is dying, and they leave children. These children are in responsibility of the government... These are children who need assistance" FP_02_GCSAM.

"At the entrance door... we do medical care, right? Then comes the legal part, but unfortunately most of our victims do not complaint",FP_01_HM.

"I'll complain to my husband and then I'Il come back. I share the bed with him. I'll complain to my husband then I'll come back and share the table with him. I think there is one here... we must overcome this taboo and let people free themselves and start to live life", FP_01_IM.

\section{Discussion}

\section{Documents alignment with national policies}

The political and institutional sectors will to control and prevent DV is evident from the number of existing guidelines, protocols, pamphlets and brochures developed. However, the lack of guidelines at care services sites can be linked with lack of financial and human resources suitably qualified and committed to addressing the DV-related issues,compromising adequate implementation as well as monitoring and evaluation of national strategies $[28,30,34,35]$. Simultaneously, the low qualification of professionals providing care to survivors of DV is influenced by negative socio-cultural factors and demographic characteristics such as sex and age [36-38]. These factors undermine the non-judgmental, empathetic, and understandable approach $[39,40]$. The lack of financial and human resources can also be co-substantiated by the fact that CSOs, where funding does not depend on general state funds, frequently design and disseminate DV prevention and control messages. Another example of the lack of government investment, is the existence of guidelines co-financed by a CSO. This is related to the management of sexual violence against children in almost all health facilities. Some studies have shown that although health sector financing is decentralised from state funds, the health sector did not plan a specific budget allocated to DV-related activities [41].

Besides the number of guidelines and protocols developed, it is crucial their content is aligned with recommendations of national and international policies advocating for comprehensive and adequate responses to DV. Furthermore, information included in these documents must be written and structured in such a way as to facilitate understanding and implementation of activities in all sectors involved $[6,9]$.

In general, the national legal documents have some limitations that may hamper its implementation. A few are focused on primary prevention, while most of them are focused on secondary prevention, compromising in some way the control over the occurrence of new violent episodes [18, $42,43]$. This can, to some extent, support our results. Although care for survivors of violence is advocated, little is done to operationalise the needed care and provide outreach to violence survivors. Another limitation is the lack of strategies for monitoring and evaluating DV prevention and control activities in the national legal documents, which could be one of the causes of the gap found in the translation of policies into practice [18].There is a noticeable divergence regarding the content of documents under review. This may on one hand be justified by the specificity of the issues addressed in the guidelines, protocols, pamphlets and brochures. Part of this material has been designed to guide assistance or prevention activities, without other institutions' involvement, thus compromising the multisectoral approach. This fact institutionalises the strategies for the prevention and control of DV, dispersing efforts, and compromising the rationalisation of resource use[15, 34, 44-46].

\section{Relevance of guidelines and protocols}

It is known that government has developed laws and policies to fight against DV and the recognition of the relevance of these legal frameworks by providers is a demonstration of the commitment to combat and prevent DV. Nevertheless, the gaps in the development of guidelines and care protocols for DV survivors' were manifested. As the WHO recommends for adequate care to DV survivors, consistency at the various levels of action is crucial, specifically at the state (the central level), the care providers (which includes not only the infrastructure but also the existence of qualified human resources to provide care) and the users of these services, in this case the survivors [33]. . This has also been described in some studies, where government changes have increased the political will to address DV from the top down to the care provider level. This reinforces the integrated and standardised care provision by ensuring advocacy, implementation, monitoring and evaluation of these instruments [47-49].

\section{Guidelines and protocols gaps and constrains}

Responsiveness of the legal framework for DV - not only in terms of protecting the victim and punishing the aggressor - it also ensures responses are integrated which is crucial. Several factors have been described as key to the successful implementation of guidelines and protocols for addressing survivors of violence [19, 50-52].

Some studies describe the lack of compatibility between the offense and the lightness of punishment given to the aggressor during judgement. This highlights the urgent need to conduct reforms in legislation [51, 53]. However, there is a recognition that enforcement of legislation is

Page 8/16 
sometimes difficult. In short, DV survivors lack information on existing legal proceedings, and generally speaking, there is a palpable unwillingness to penalise offenders. On the other hand, severe punishments including imprisonment of the perpetrators, high economic dependence of the survivors and socio-cultural attitudes of patriarchal dominance are factors likely to be related to the survivors' failure to report on the event of violence and to the suspension of the judicial process [23, 53-59].

Given that DV is a multi-causal phenomenon, it is critical legislation reforms accommodate the contributions not only of the policy implementers, but also of DV survivors and communities in general. In order to ensure this, integrated and comprehensive interventions must be provided and accepted. CSOs should be included in this integrated approach, as these are often the gateway to the DV care provision system, given its connectivity with communities $[6,60]$. In addition to community education and advocacy, CSOs also provide safety of DV survivors and their children by providing shelters $[61,62]$.

Therefore, it is essential, that care provided by these organisations can be detailed in a specific field of the standardised form recommended by the multisectoral mechanism for assisting survivors of violence in Mozambique. Herewith any other caregiver will be able to understand what assistance has been given to the victim at the CSO level. The inclusion of this field could encourage the continuity of care provision activities related to improving monitoring of the multisectoral mechanism[18, 63].

Also, given the fact some institutions have their own DV logbook generating various sources of information, thus compromising the implementation of DV prevention strategies using the integrated approach.. This fact can jeopardise DV data and dissemination of information. Therefore, the strategy design and policies for the prevention and control of DV, must be based on evidence[18, 64].

Adequate implementation of policies and strategies for the prevention and control of DV, implies reasonable and adequately trained human resources. The lack of training of professionals is an obstacle compromising not only the understanding and applicability of policies and legislation on DV, but also the follow-up of DV cases. The poor performance of care service providers, was noticeable when questioning the events of violence and the willingness of the survivor to access other services which are part of the integrated care service[22, 56-57].

Given the context of Mozambique and many other African countries, the influence of negative socio-cultural factors on the attitudes and practices of implementers regarding care provision for DV survivors is remarkable. These factors function as barriers to develop help seeking behaviour which may increase DV survivors internalisation or anticipation of stigma $[67,68]$.

The facts described above were used by Gilson and Walt to develop a model of a policy analysis. In this model, they suggest incorporation of the policies context, content and process. Context refers to the environment in which the policy to be analyzed is inserted. Therefore, this process is a step by step policies design, implementation and if necessary, its reform. In addition to the components previously described, the authors recognise that a great deal of emphasis is being placed on the content of policies neglecting the role of the policy-makers or implementers considered indispensable for the success of this model $[69,70]$.

Although the study has brought some relevant aspects in the design, and implementation of the guidelines, the lack of awareness of some focal points was noticeable. This weakeness was mostly related with the study that inclusion criteria that considered only the documents was posted in the study sites. Therefore it was difficult to link focal point awareness as well as whether or not documents cited by focal points with the quality of its implementation.

\section{Conclusions}

Although government commitment to mitigate DV is noteworthy given the amount of national policies, laws and strategic plans, guidelines and protocols produced. However, there is a dearth of guidelines, protocols, pamphlets and brochures in places providing care for survivors of violence. This makes it difficult to standardise and integrate these services. In addition, there was a misalignment between guidelines and protocols of attendance with policies, laws and strategic plans regarding their content and terminology used in their titles.

One of the strengths to promote DV control and prevention is recognition of the relevance of guidelines and protocols by gender focal points. However, they are aware of the gaps compromising its proper implementation, so care delivery is adequate and timely. These facts lead us to recognise the lack of prioritisation in the governmental agenda, and reinforce the need to monitor and evaluate the policies, laws, and strategic plans. This study also recognises the need to reform existing legislation, coupled with allocating an appropriate budget to ensure a proper strategies implementation and improving the survivors' quality of life.

\section{List Of Abbreviations}

DV- Domestic Violence

WHO- World Health Organisation 
IMASIDA- Inquérito de Indicadores de Imunização, Malária e HIV/SIDA em Moçambique ((Survey of the Indicators for Immunization, Malaria and HIV/AIDS in Mozambique)

CSO- Civil Society Organisation

PAHO- Pan-American Health Organisation

UN-United Nations

\section{Declarations}

\section{Competing interests}

All authors declare they have no competing interests.

\section{Authors' contributions}

EJ was responsible for conception and design, acquisition of data, analysis interpretation of data as well as the writing of the initial manuscript. Additionally, IK, EM, MS and KR contributed to the study design, data analysis and critically revised the manuscript for important scientific content.

All authors read and approved the final manuscript.

\section{Ethical approval and consent to participate}

The study was approved in 2016 by the Institutional committee of the Faculty of Medicine and the National Bioethics Committee of Mozambique (Ref: IRB00002657) and all ethical aspects recommended by the committee were strictly followed. Formal authorisation to conduct the study was previously requested firstly to the Ministry of Health then to Provincial and community authorities. After explaining the study objectives and procedures, gender focal points were invited to voluntary participate in the study and their participation was confirmed by signing the informed consent.

\section{Acknowledgements}

We gratefully acknowledge the contributions of the domestic violence focal points from governmental and non-governmental institutions; to the DESAFIO Program - Eduardo Mondlane University and the International Centre for Reproductive Health, Belgium - Ghent University, for technical and financial support; To Prof. Gabriela Santos-Gomes for technical support and contributions provided to the study; And To Neal McKenna for editing.

The manuscript editing and publication was supported by Fogarty International Center, Office of the Director, Eunice Kennedy Shriver National Institute of Child Health \& Human Development and National Institute of Neurological Disorders and Stroke of the National Institutes of Health under Award Number D43TW010135. The content is solely the responsibility of the authors and does not necessarily represent the official views of the Fogarty International Center or the National Institutes of Health.

\section{Funding}

This study is financially supported by VLIR-OUS in collaboration with Eduardo Mondlane University, Mozambique. The funders had no role in the study design, data collection, analysis or interpretation of data and in writing of the manuscript.

\section{Consent for publication}

Not Applicable

\section{Availability of data and materials}

Datasets used and/or analysed during this study are available from the corresponding author upon reasonable request.

\section{References}

1. Babu B V., Kar SK. Domestic violence in Eastern India: Factors associated with victimization and perpetration. Public Health. 2010;124:13648. doi:10.1016/j.puhe.2010.01.014. 
2. World Health Organization. Global and regional estimates of violence against women: prevalence and health effects of intimate partner violence and non-partner sexual violence. Geneva, Switzerland:2013;57; ISBN: 9789241564625.

https://apps.who.int/iris/bitstream/handle/10665/85239/9789241564625_eng.pdf. Accessed: 20 January 2016.

3. Bravo MMP, Martínez PA, Ruiz IJ. Public Policies, Nursing Role and Health Programs Against Gender Violence. Comparative Study Spain Brazil. Procedia - Social and Behavioral. Sciences.2017;237:758-764. http://dx.doi.org/10.1016/j.sbspro.2017.02.118. Retrieved from http://linkinghub.elsevier.com/retrieve/pii/S1877042817301180.

4. Tenkorang EY, Owusu A, Yeboah EH. Factors Influencing Domestic and Marital Violence against Women in Ghana Factors Influencing Domestic and Marital Violence against Women in Ghana. 2013;28:771-81. doi:10.1007/s10896-013-9543-8; ISBN: 1089601395.

5. Mccloskey LA, Hunter T. Determinants of Intimate Partner Violence in Sub-Saharan Africa: A Review of Prevention and Intervention Programs.Partner Abuse.2016;7(3):277-315.doi: 10.1891/1946-6560.7.3.277.

6. World Health Organization. Understanding and addressing violence against women. Geneva, Switzerland. 2012;1-8. Retrieved from: http://www.who.int/iris/handle/10665/77428.

7. Dutton DG, Nicholls TL, Spidel A. Female perpetrators of intimate abuse. Women Who Perpetrate Relatsh Violence Mov Beyond Polit Correctness. 2014;41(4):1-31.doi: 10.4324/9781315864419-7; ISBN: 9781317954637

8. Archer J. Sex differences in aggression between heterosexual partners: A meta-analytic review. Psychol Bull. 2000;126(5):651-80.doi: 10.1037/0033-2909.126.5.651; ISSN: 00332909.

9. Heise L, Ellsberg M. Ending violence against Women. Population Information Program. 1999; 28(4):45. doi:10.1080/15211030802194589.

10. Heise L, Ellsberg M, Gottmoeller M. A global overview of gender-based violence. International Journal of Gynecology and Obstetrics.2002;78(1):1-10.

11. Garcia-moreno C, Jansen HAFM, Ellsberg M, Heise L, Watts $\mathrm{CH}$, Study WHOM. Prevalence of intimate partner violence: fi ndings from the WHO multi-country study on women 's health and domestic. 2006;368:10.

12. World Health Organization. WHO Multi-country Study on Women's Health and Domestic Violence against Women: Initial results on prevalence, health outcomes and women's responses. 2005;151:277-83. doi:10.1016/S0140-6736(06)69523-8.

13. United Nations Children's Fund, Domestic Violence Against Women And Girls.Innocenti Research Center. Florence, Italy. 2000;6:1-30.

14. Cools S, Kotsadam A. Resources and Intimate Partner Violence in Sub-Saharan Africa. Elsevier, World Development. 2017;95:1-30. doi:10.1016/j.worlddev.2017.02.027.ISSN: 0305-750X. Retrieved from: http://dx.doi.org/10.1016/j.worlddev.2017.02.027.

15. Borwankar R., Diallo R., and Sommerfelt A.E. Gender- based Violence in sub-Saharan Africa: A review of Demographic and Health Survey findings and their use in National Planning. 2008. Washington DC: USAID/AFR/SD and Africa's Health in 2010/AED:1-18.

16. Instituto Nacional de Estatítica, Ministério da Saúde. Moçambique: Inquérito Demográfico e de Sáude. Maputo, Moçambique. $2013: 430$. Retrieved from https://dhsprogram.com/pubs/pdf/FR266/FR266.pdf.

17. Ministério da Saúde, Instituto Nacional de Estatística, ICF International. Inquérito de Indicadores de Imunização, Malária e HIV/SIDA em Moçambique, Relatório final. Maputo, Moçambique. 2018:453. Retrieved from https://dhsprogram.com/pubs/pdf/AIS12/AIS12.pdf.

18. República de Moçambique. Mecanismo Multisectorial De Atendimento Integrado À Mulher Vítima De Violência. 2012;1-77. Retrieved from: http://www.wlsa.org.mz/wp-content/uploads/2014/11/MecanismoMultisectorial.pdf.

19. Schopper D, Lormand JD,Waxweiler R. Developing policies to prevent injuries and violence: guidelines for policy-makers and planners. World Health Organization.Geneva, Switzerland.2006;1-85.ISBN: 9241593504.

20. World Health Organization. Violence prevention, The evidence: Series of briefings on violence prevention. Geneva, Switzerland. 2010;1130.ISBN: 9789241500845.

21. Ali PA, Gavino MIB. Violence against women in Pakistan: A framework for analysis. Journal of the Pakistan Medical Association. 2008;58(4):1-6.ISSN: 00309982.

22. Romão F., Mabunda L., Buque C., Samo G. VO. Violence Against Women in Mozambique. United Nations Dev Fund Women. $2009: 1-20$.

23. Oxfam. Changing Laws, Changing Lives: Supporting Survivors of Gender-Based Violence in Mozambique.Oxford, United Kingdom. $2015 ; 7$.

24. Hien D, Ruglass L. Interpersonal partner violence and women in the United States: An overview of prevalence rates, psychiatric correlates and consequences and barriers to help seeking. International Journal of Law and Psychiatry. 2009;32(1):48-55. doi:10.1016/j.ijlp.2008.11.003.

25. Hollenshead JH, Dai Y, Ragsdale MK, Massey E, Scott R. Relationship between two types of help seeking behavior in domestic violence victims. Journal of Family Violence. 2006;21:271-279. doi:10.1007/s10896-006-9021-7.

26. Slegh H. Gender-based violence and women 's search for care in Mozambique. 2010;22(1):109-124.

27. República de Moçambique. Boletim da República.Diploma Ministerial n. ${ }^{\circ}$ 36/2012:Bol da República. 2012; I Série:1-12. Retrieved from: extwprlegs1.fao.org/docs/pdf/moz120466.pdf.

28. Hayati EN, Emmelin M, Eriksson M. Challenges for a local service agency to address domestic violence - A case study from rural indonesia. Global Journal of Health Science. 2014;6(5):1-12. doi:10.5539/gjhs.v6n5p214.

Page $11 / 16$ 
29. United Nations Development Programme. A Toolkit for Strengthening Partnerships. 2006:1-94.

30. Solano, P. Velzeboer. Componentes Clave En La Formulación De Leyes Y Políticas Contra La Violencia Hacia Las Mujeres (Documento De Discusión ), Pan-American Health Organization, Gender and Health Unit. Washington DC, USA. 2003;1-25.

31. United Nations, Department of Economic and Social Affairs, Division for the Advancement of Women . Handbook for Legislations on Violence against Women.New York, USA. 2010;1-65.ISBN: 9789211302905

http://onlinelibrary.wiley.com/doi/10.1002/cbdv.200490137/abstract\%5Cnhttp://www.un.org/womenwatch/daw/vaw/handbook/Handbook for legislation on violence against women.pdf.

32. Haahr M. "True Random Integer Generator." RANDOM.ORG: True Random Number Service. Randomness and Integrity Services Ltd. 2020.

33. Elo S. \& Kyngas H. The qualitative content analysis process. Journal of Advanced Nursing.2008; 62(1), 107-115 doi: 10.1111/j.13652648.2007.04569.x.ISSN: 03092402.

34. Colombini M, Dockerty C, Mayhew SH. Barriers and Facilitators to Integrating Health Service Responses to Intimate Partner Violence in Lowand Middle-Income Countries: A Comparative Health Systems and Service Analysis. Studies in Family Planning. 2017;1-7. doi:10.1111/sifp.12021. Retrieved from: http://doi.wiley.com/10.1111/sifp.12021.

35. Gear C, Koziol-McLain J, Wilson D, Clark F. Developing a response to family violence in primary health care: The New Zealand experience. BMC Fam Pract. 2016;17:1-9. doi:10.1186/s12875-016-0508-x.

36. Lucea MB, Stockman JK, Mana-Ay M, Bertrand D, Callwood GB, Coverston CR, et al. Factors Influencing Resource Use by African American and African Caribbean Women Disclosing Intimate Partner Violence. J Interpers Violence. 2013;28(8):1617-41.doi: 10.1177/0886260512468326.ISSN: 08862605

37. Ahmed AT, McCaw BR. Mental health services utilization among women experiencing intimate partner violence. Am J Manag Care. 2010;16(10):731-8.ISSN: 10880224.

38. Lawoko S, Sanz S, Helström L, Castren M. Screening for Intimate Partner Violence against Women in Healthcare Sweden: Prevalence and Determinants. ISRN Nurs. 2011;2011:1-7.doi: 10.5402/2011/510692. ISSN: 2090-5483.

39. Feder GS, Hutson M, Ramsay J, Taket A. Women Exposed to Intimate Partner Violence. Arch Intern Med. 2006;166(1):22.doi: 10.1001/archinte.166.1.22.ISSN: 0003-9926.

40. Agenagnew L, Tebeje B, Tilahun R. Disclosure of Intimate Partner Violence and Associated Factors among Victimized Women, Ethiopia, 2018: A Community-Based Study. Int J Reprod Med. 2020;2020:1-9.doi: 10.1155/2020/6513246. ISSN: 2356-7104.

41. Le TM, Morley C, Hill PS, Bui QT, Dunne MP. The evolution of domestic violence prevention and control in Vietnam from 2003 to 2018 : a case study of policy development and implementation within the health system. Int J Ment Health Syst. 2019;1-16. doi:10.1186/s13033-0190295-6.

42. República de Moçambique. Orgânica da Assembleia da República. Boletim da República. 2009.I(38):5. Retrieved from http://www.wlsa.org.mz/leisnacionais.

43. República de Moçambique. Plano Nacional De Acção Para O Avanço Da Mulher 2007-2009.Boletim da República.2007

44. World Health Organization. Responding to intimate partner violence and sexual violence against women, WHO clinical and policy guidelines.Geneva, Switzerland.2013;1-68. doi:10.1136/bmj.f3100; ISBN: 9789241548595. Retrieved from: http://www.who.int/reproductivehealth/publications/violence/9789241548595/en/.

45. World Health Organization. Strengthening health systems to respond to women subjected to intimate partner violence or sexual violence: a manual for health managers. Geneva, Switzerland.2017;1-172;ISBN: 9789241513005.

46. Ostlin P, Eckermann E, Mishra US, Nkowane M, Wallstam E. Gender and health promotion: A multisectoral policy approach. Health Promotion International. 2006; 21(1):25-35.doi: 10.1093/heapro/dal048; ISBN: 1460-2245 (Electronic) \r0957-4824 (Linking).

47. Colombini M, Mayhew SH, Lund R, Singh N, Swahnberg K, Infanti J, et al. Factors shaping political priorities for violence against womenmitigation policies in Sri Lanka. BMC International Health and Human Rights. 2018;18(1):1-12.doi: 10.1186/s12914-018-0161-7;ISSN: 1472698X.

48. United Nations Entity for Gender Equality and Empowerment of Women. Good Practices in National Action Plans. 2010;1-83.

49. Colombini M, Mayhew SH, Hawkins B, Bista M, Joshi SK, Schei B, et al. Agenda setting and framing of gender-based violence in Nepal: How it became a health issue. Health Policy and Planning. 2016;31(4):493-503.doi: 10.1093/heapol/czv091;ISBN: 0939253747.

50. Kulwicki A, Aswad B, Carmona T, Ballout S. Barriers in the Utilization of Domestic Violence Services Among Arab Immigrant Women: Perceptions of Professionals, Service Providers \& Community Leaders. J Fam Violence. 2010;25:727-35. doi: 10.1007/s10896-010-9330-8; ISBN: 1089601093.

51. Yigzaw T, Yibric A, Kebede Y. Domestic violence around Gondar in Northwest Ethiopia. Ethiopian Journal of Health and Development. 2005;18(3):1-8.doi: 10.4314/ejhd.v18i3.9846. 
52. Deribe K, Beyene BK, Tolla A, Memiah P, Biadgilign S, Amberbir A. Magnitude and correlates of intimate partner violence against women and its outcome in Southwest Ethiopia. PLoS One. 2012;7(4);1-7.doi: 10.1371/journal.pone.0036189;ISSN: 19326203.

53. Semahegn A, Torpey K, Manu A, Assefa N, Tesfaye G, Ankomah A. Are interventions focused on gender-norms effective in preventing domestic violence against women in low and lower-middle income countries? A systematic review and meta-analysis. Reproductive Health. 2019;16(1):1-31. doi: 10.1186/s12978-019-0726-5;ISBN: 4201707997.

54. Bohmer C, Brandt J, Bronson D, Hartnett H. Domestic violence law reforms: Reactions from the trenches. Journal of Sociology \& Social Welfar. 2002;29(3):1-19.ISSN: 0191-5096.

55. United Nations Development Programme. From Commitment to Action: Policies to End Violence Against Women in Latin America and the Caribbean.Panamá.2017:45.ISBN: 9789962688389.

56. Mogale RS, Burns KK, Richter S. Violence Against Women in South Africa: Policy Position and Recommendations. Violence Against Women,SAGE. 2012;18(5):580-94.doi: 10.1177/1077801212453430; ISSN: 10778012.

57. Alangea DO, Addo-Lartey AA, Sikweyiya Y, Chirwa ED, Coker-Appiah D, Jewkes R, et al. Prevalence and risk factors of intimate partner violence among women in four districts of the central region of Ghana: Baseline findings from a cluster randomised controlled trial. PLoS One. 2018;13(7):1-19. doi: 10.1371/journal.pone.0200874; ISSN: 19326203.

58. Decker MR, Frattaroli S, McCaw B,. Coker AL, Miller E, Sharps P, et al. Transforming the Healthcare Response to Intimate Partner Violence and Taking Best Practices to Scale. 2012;21(12):1222-1229.doi: 10.1089/jwh.2012.4058.

59. United states Agency for International Development. Gender-Based Violence in Tanzania : an Assessment of Policies , Services , and Promising Interventions. 2008:1-55.

60. World Health Oganization. Global Status Report on Violence Prevention 2014. Geneva, Switerzland. 2014:1-274. doi:10.1007/s13398-0140173-7.2; ISBN: 97892415647939241564792 . Retrieved from:

http://www.who.int/violence_injury_prevention/violence/status_report/2014/en//..

61. Sullivan CM. Understanding How Domestic Violence Support Services Promote Survivor Well-being: A Conceptual Model. Journal of Family Violence. 2018:123-31.doi: 10.1007/s10896-017-9931-6.

62. Beninger $\mathrm{C}$. The effectiveness of legislative reform in combating domestic violence: A comparative analysis of laws in ghana, Namibia and South Africa. Netherlands Quarterly of Human Rights. 2014;32( 1):75-108. ISSN: 01693441.

63. Davis RE, Harsh KE. Confronting barriers to Universal screening for domestic violence. Journal ofProfessional Nursing. 2001;17(6):313-320. doi: 10.1053/jpnu.2001.28181; ISBN 8755-7223 (Print)\r8755-7223 (Linking).

64. National Center Against Violence. Implementation of Mongolia's Domestic Violence Legislation.Ulaanbaatan, Mongolia. 2014:1-109.ISBN: 0929293738.

65. World Health Organization. Reducing violence through victim identification , care and support programmes.Geneva, Switerzland.2009:1-20. ISBN:978 9241598477.

66. Jewkes, R., Gibbs, A., Jama-Shai, N., Willan S., Mushinga, M. et al. Stepping stones and creating futures intervention: shortened interrupted time series evaluation of a behavioural and structural health promotion and violence prevention intervention for young people in informal settlements in Durban, South Africa BMC. BMC Public Heal 2014. 2014;14:1-20.

67. Overstreet NM, Quinn DM. The Intimate Partner Violence Stigmatization Model and Barriers to Help-Seeking. Basic Appl Soc Psych. 2013;35 June 2014:109-22. doi:10.1080/01973533.2012.746599.

68. Alsaedi JA, Elbarrany WG, Ahmed W, Majnon AL, Al-namankany AA. Barriers that Impede Primary Health Care Physicians from Screening Women for Domestic Violence at Makkah ALmukarramah City. The Egyptian Journal of Hospital Medicine. 2017;69(8):3058-3065. doi: $10.12816 / 0042856$.

69. Walt G, Shiffman J, Schneider H, Murray SF, Brugha R. ' Doing ' health policy analysis: methodological and conceptual reflections and challenges. Health Policy and Planning 2008;23:308-317. doi: 10.1093/heapol/czn024.

70. Walt G, Gilson L. Review article Reforming the health sector in developing countries: the central role of policy analysis. Health Policy and Planning. 1994; 9(4):353-370. doi: https://doi.org/10.1093/heapol/9.4.353..

71. República de Moçambique. Boletim da República. Lei de Prevenção e Combate as Uniões Prematuras em Moçambique.2019;l(203):8. Retrieved from: https://www.unicef.org/mozambique/relatorios/lei-de-prevenção-e-combate-uniões-prematuras-em-moçambique.

\section{Figures}




\begin{tabular}{|c|c|c|c|c|c|}
\hline \multirow{2}{*}{$\begin{array}{l}\text { Central } \\
\text { Level }\end{array}$} & \multicolumn{4}{|c|}{ Ministry of Gender Children and Social Action } & \multirow[b]{2}{*}{ Civil Society } \\
\hline & Ministry of & ealth & Ministry & Interior & \\
\hline $\begin{array}{l}\text { Care } \\
\text { providers } \\
\text { Level }\end{array}$ & $\begin{array}{l}\text { Maputo Cidade } \\
\text {-General Hospital : } \\
\text { José Macamo, } \\
\text { Chamanculo, } \\
\text { Polana Caniço } \\
\text {-Health Centers: } \\
\text { Xipamanine, } \\
\text { Albazine, } \\
\text { Maxaquene, } 1^{0} \text { de } \\
\text { Maio, Porto, } \\
\text { Malhangalene, } \\
\text { Zimpeto, } 1^{0} \text { de } \\
\text { Junho } \\
\text {-Integrated Service } \\
\text { Centers: José } \\
\text { Macamo, } \\
\text { Bagamoyo }\end{array}$ & $\begin{array}{l}\text { Quelimane } \\
\text { - Provincial } \\
\text { Hospital: One } \\
\text { Stop- } \\
\text { Integrated } \\
\text { Services) } \\
\text {-Health } \\
\text { Centers: } 4 \text { de } \\
\text { Dezembro, } \\
\text { Namuínho, } \\
\text { Micajune }\end{array}$ & $\begin{array}{l}\text { Maputo } \\
\text { Cidade } \\
\text { - Police help } \\
\text { centers for } \\
\text { victims of } \\
\text { DV: } \\
1,3,6,7,16,17 \\
18 \text { Police } \\
\text { stations. } \\
\text { - Department } \\
\text { of } \\
\text { Attendance } \\
\text { of Family and } \\
\text { Children } \\
\text { Victims of } \\
\text { Violence }\end{array}$ & $\begin{array}{l}\text { Quelimane } \\
\text { - } \\
\text { Department } \\
\text { of } \\
\text { Attendance } \\
\text { of Family } \\
\text { and children } \\
\text { victims of } \\
\text { violence }\end{array}$ & $\begin{array}{l}\text { Maputo } \\
\text { - WLSA, Forum } \\
\text { Mulher, Avima, } \\
\text { Muleide, } \\
\text { Associação das } \\
\text { Vítimas de } \\
\text { Violência } \\
\text { Doméstica, } \\
\text { Xicanhewe, } \\
\text { Phuka U Hanya, } \\
\text { Kutenga } \\
\text { Quelimane } \\
\text { - AMME, Nafeza }\end{array}$ \\
\hline
\end{tabular}

Figure 1

Institutions included in the study.

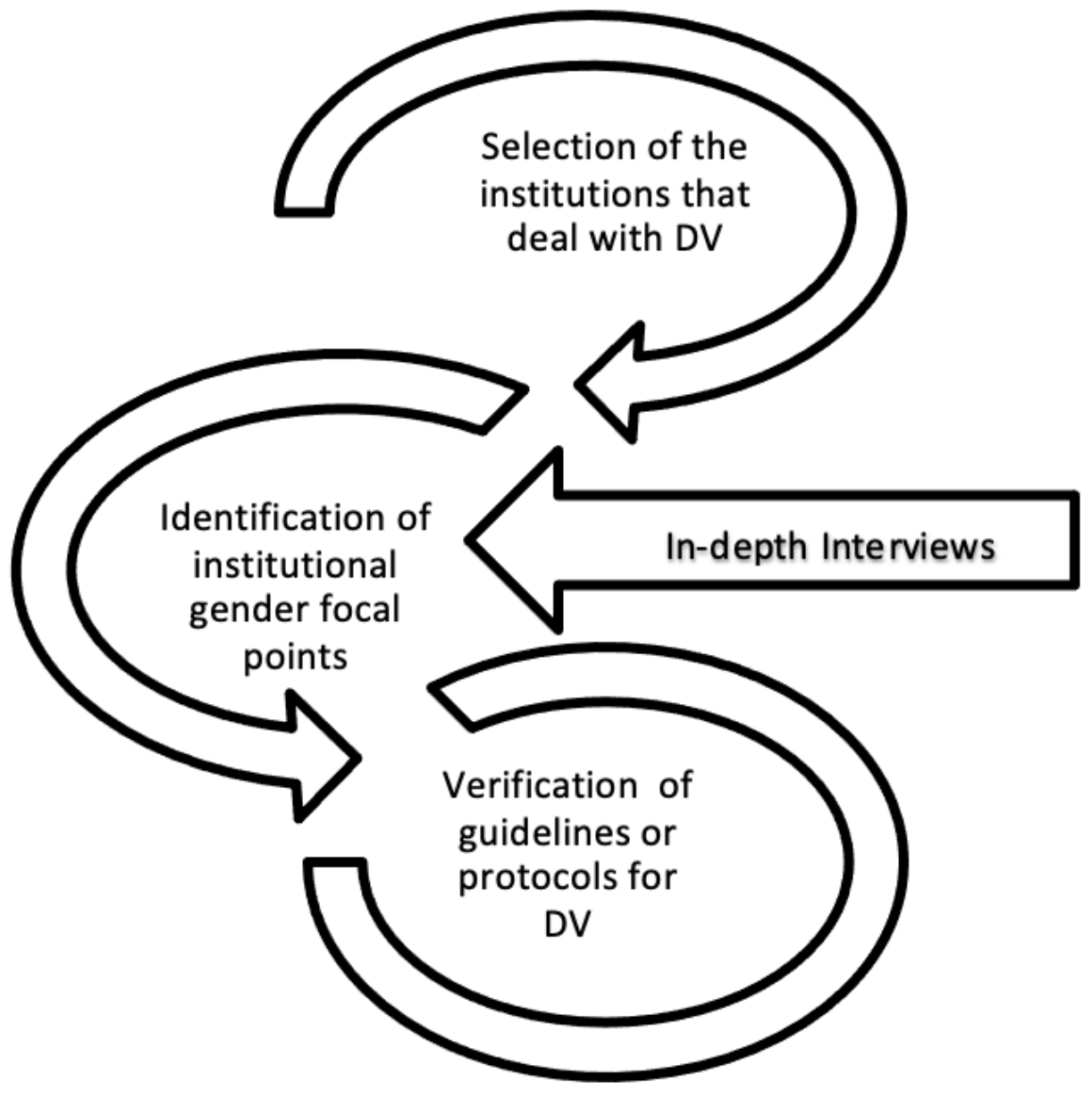


Figure 2

Study data collection procedures

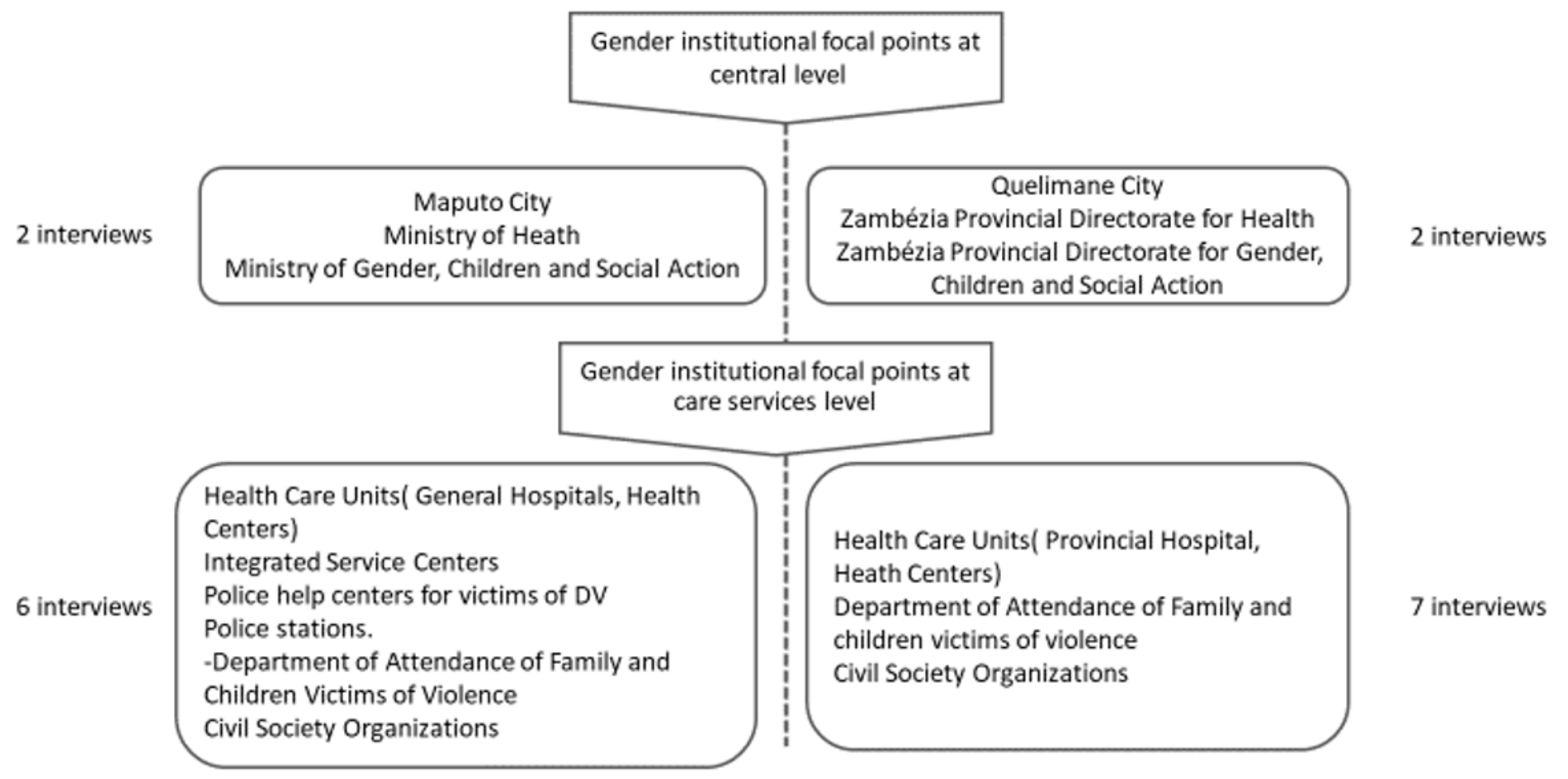

Figure 3

In depth-interviews with gender focal points at different levels of care in Maputo and Quelimane cities.
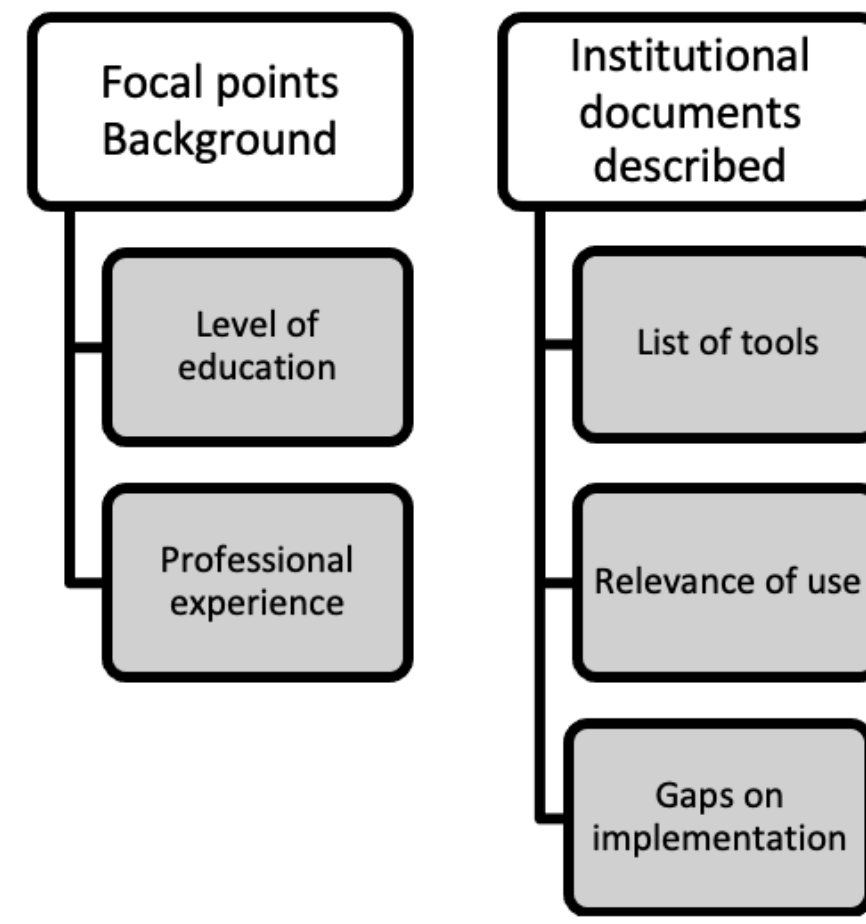

- Data management

- Tolls design

- Human resources

- Influence of socio-cultural factors

- Adequacy of the infrastructures

Figure 4 
Nodes and sub-nodes used to perform the data analysis

Page 16/16 